\title{
Estudos histopatológicos de Colletotrichum spp. em plântulas de cafeeiro
}

\author{
Severina R.O. Lins, Mário S. Abreu \& Eduardo Alves \\ Departamento de Fitopatologia, Universidade Federal de Lavras, Cx. Postal 3037, CEP 37.200-000, Lavras, MG, \\ Brasil, e-mail: ealves@ufla.br
}

Autor para correspondência: Eduardo Alves

LINS, S.R.O., ALVES, E. \& ABREU, M. S. Estudos histopatológicos de Colletotrichum spp. em plântulas de cafeeiro. Fitopatologia Brasileira 32:488-495. 2007.

\section{RESUMO}

Objetivou-se neste trabalho, acompanhar pela microscopia eletrônica de varredura, os processos de infecção, colonização e reprodução de diferentes isolados de Colletotrichum spp. em plântulas de cafeeiro. Plântulas da cultivar Rubi

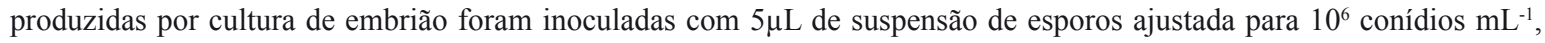
na região do hipocótilo e folhas, após ferimento com agulha entomológica. Os isolados avaliados foram Colletotrichum gloeosporioides (IH), obtido de ramos e (IF) de folhas de planta de café com sintomas de mancha manteigosa, C. dematium (ID) de cafeeiro sadio e C. gloeosporioides (IM) de casca de manga com sintomas de antracnose. Duas horas após as inoculações (HAI), fragmentos de folhas e hipocótilos foram transferidos para microtubos de 1,5mL contendo solução fixadora de Karnovsky modificado. As demais amostras foram coletadas 3, 5, 12, 16, 24, 48, 72, 96, 114 e 144 HAI. Os conídios de todos os isolados aderiram preferencialmente nas depressões dos órgãos inoculados, formando um septo e germinando cinco HAI (C. gloeosporioides) e doze HAI (C. dematium) emitindo tubos germinativos, tanto nas extremidades como lateralmente. Apressórios globosos, trilobulados, em forma de pé e de vírgula foram produzidos apenas por C. dematium (ID), 12 HAI; enquanto que C. gloeosporioides (IF), produziu apressórios globosos $24 \mathrm{HAI}$; os demais isolados não produziram apressórios. C. gloeosporioides isolados IH, IF e IM produziram células conidiogênicas $48 \mathrm{HAI}$. Acérvulos foram produzidos $72 \mathrm{HAI}$, por $C$. gloeosporioides $(\mathrm{IH})$ e 96 horas por $C$. dematium. O isolado IM colonizou tecidos de plantas de cafeeiro, produzindo conidióforos, no entanto, sem produção de acérvulo. Os isolados mais agressivos foram IH e IF.

Palavras-chave adicionais: mancha manteigosa, microscopia eletrônica de varredura, Colletotrichum gloeosporioides, Colletotrichum dematium.

\begin{abstract}
Histopathologic study of Colletotrichum spp. in coffee plantlets

The objective of this work was to follow the process of infection, colonization and reproduction of different isolates of Colletotrichum spp. in coffee plantlets, obtained by embryo culture, using scanning electron microscopy. The embryo explants were obtained from coffee seeds cv. Rubi. Plants produced in vitro were inoculated with $5 \mu \mathrm{L}$ of a $10^{6} \mathrm{conidia}^{\mathrm{mL}} \mathrm{mL}^{-1}$ spore suspension, on the hypocotyl region and leaves, wounding with an entomological needle. Isolates of Colletotrichum gloesporioides were obtained from stem (IS) and leaves (IL) from plants with symptoms of greasy leaf spot, and from mangos with symptoms of anthracnose (IM). Isolates of Colletotrichum dematium were obtained from healthy coffee plants. Three hours after inoculation (h.a.i.), leaves and hypocotyl fragments were transferred to $1.5 \mathrm{~mL}$-microtubes containing modified Karnovsky`s fixative solution. Further samples were collected at 3, 5, 12, 16, 24, 48, 72, 96, 114 and 144 h.a.i. Conidia of all isolates adhered more frequently in the depressions of hypocotyls and guard-cells, forming a septum 5 h.a.i. Germ tubes were observed 12 h.a.i. starting from the extremities as well as laterally in the conidia. Appressoria were produced by $C$. dematium (globoses, trilobullated and foot and comma-shaped), and C. gloeosporioides, respectively globoses, 24 h.a.i. C. gloeosporioides (IH and IF) produced conidiogenic cells 48 h.a.i. Acervuli were produced 72 h.a.i. by C. gloeosporioides (IH), 96 h.a.i. by C. dematium. C. gloeosporioides isolated from mango colonized coffee plant tissues, producing conidiogenic cells without production of acervuli. The most aggressive isolates were IS and IL.

Additional keywords: greasy leaf spot, scanning electronic microscopy, Colletotrichum gloeosporioides, Colletotrichum dematium.
\end{abstract}

\section{INTRODUÇÃO}

Colletotrichum é um gênero de fungo ascomiceto que engloba muitas espécies causadoras de doenças em

Parte da Dissertação de Mestrado do primeiro autor. Universidade Federal de Lavras. Lavras MG. 2006. uma gama extensiva de hospedeiros (Bailey \& Jeger, 1992). Espécies deste gênero apresentam diversas estratégias na invasão dos tecidos de plantas, que vão de hemicelular hemibiotrófica a intramural intracelular necrotrófica. Além disso, estes patógenos desenvolvem uma série de estruturas de infecção especializadas, incluindo tubos germinativos, apressórios, haustórios, hifas intracelulares necrotróficas secundárias e acérvulos (Sutton, 1980). Fungos do gênero 
Colletotrichum são tidos como modelos para processos de infecções, competindo com Phytophthora como o gênero patogênico de plantas mais estudado (Bailey \& Jeger, 1992).

Em conídios de Colletotrichum graminicola e Colletotrichum truncatum a germinação inicia-se com a formação de um septo e é precedida por uma mitose (Skoropad, 1967; Staples et al., 1976). Após o núcleo movese pelo tubo germinativo, onde passa por uma segunda mitose e um segundo septo é formado; então a célula da ponta do tubo germinativo se desenvolve em um segmento de hifa para formar o apressório. Posteriormente ocorre uma mitose e é produzido um apressório binucleado maduro que vai formar a hifa infectiva.

Em cafeeiro, um grande número de espécies de Colletotrichum são encontradas, sendo patogênicas ou endófitas. Alguns estudos realizados com espécies patogênicas enfocam o efeito da temperatura e umidade nos processos de desenvolvimento e formação de estruturas de penetração (Dillard, 1989; Garcia, 1999; Estrada et al., 2000; Chen et al., 2004; Dias et al., 2005; Pereira et al., 2005). Entretanto, poucos enfocam estudos microscópicos dos processos de desenvolvimento, colonização e reprodução em tecidos de plantas de cafeeiro.

A mancha manteigosa do cafeeiro é uma doença que tem sido atribuída a Colletotrichum gloeosporioides (Penz.) Penz. \& Sacc. No entanto, existem poucas investigações no que se refere aos processos de penetração e colonização neste patossistema. Estudos realizados até o presente, tentado a reprodutibilidade dos sintomas, não tiveram sucesso, havendo a necessidade de novas pesquisas (Orozco, 2003; Pereira et $a l ., 2005)$. O objetivo deste estudo foi acompanhar, por meio da microscopia eletrônica de varredura, os processos de infecção, colonização e reprodução de diferentes isolados de Colletotrichum, obtidos de cafeeiro e de manga em plântulas de cafeeiro.

\section{MATERIAL E MÉTODOS}

\section{Obtenção de plântulas de cafeeiro pelo método de cultura de embrião}

Foram coletadas 300 sementes de café, da cultivar Rubi, do campo experimental de pesquisa da Universidade Federal de Lavras - UFLA, no estádio verde cana, para a extração dos embriões. As sementes foram previamente selecionadas, em seguida colocadas em álcool $70 \%$ por 3 minutos e transferidas para recipiente contendo hipoclorito de sódio $2,5 \%$ onde permaneceram em agitação por 15 minutos e em seguida lavadas por duas vezes em água destilada-esterilizada. Os embriões foram extraídos das sementes intactas, em câmara de fluxo laminar horizontal sob microscópio estereoscópio, com bisturi e pinça esterilizados. Para este processo, as cascas das sementes foram cuidadosamente retiradas, passando pelo pergaminho até atingir o endosperma, o qual foi cuidadosamente fragmentado com a finalidade de se encontrar o embrião.
Os embriões foram retirados com bisturi e colocados em tubos de ensaio $(2,5 \times 15 \mathrm{~cm})$ contendo $10 \mathrm{~mL}$ de meio agar nutritivo básico de Murashige \& Skoog (1962) pH 5,9, acrescido de $6 \mathrm{mg} . \mathrm{L}^{-1}$ do hormônio de crescimento GA3 (giberelina), com $\mathrm{pH}$ ajustado para 5,9 e solidificado com ágar na proporção de $7 \mathrm{~g} / \mathrm{L}$. Os tubos contendo meio de cultura foram, previamente, vedados com tampa de polipropileno e autoclavados à temperatura de $121^{\circ} \mathrm{C}$, durante 20 minutos e $1,2 \mathrm{~atm}$, e deixados em sala a temperatura ambiente. Doze horas após realizou-se a retirada dos embriões. Apenas um embrião foi depositado em cada tubo, tendo sido coletados 240 embriões. Em seguida, o material foi transferido para sala de crescimento à temperatura de $26 \pm 1{ }^{\circ} \mathrm{C}$, fotoperíodo de 16 horas e intensidade luminosa de $16 \mathrm{M} \cdot \mathrm{m}^{-2} \cdot \mathrm{s}^{-1}$, suprida por lâmpadas grow-lux e branca fria, permanecendo nessas condições por um período de um ano. Ao final deste período, as plântulas já haviam atingido aproximadamente cinco centímetros de tamanho e emitido quatro pares de folhas, estádio em que foram inoculadas. Este procedimento foi utilizado para obtenção das plântulas livres de fungos que permitissem a observação das estruturas dos isolados de Colletotrichum inoculados nos tecidos.

\section{Obtenção dos isolados de Colletotrichum spp. e ajuste da suspensão de esporos}

Foram coletados folhas e ramos de plantas de cafeeiro da cultivar Catucaí Vermelho com sintomas de mancha manteigosa e plantas aparentemente sadias da mesma cultivar, em campo experimental da UFLA. As amostras foram acondicionadas em sacos de papel e levadas ao Laboratório de Diagnose de Enfermidades em Plantas, do Departamento de Fitopatologia da UFLA. Foram feitas secções dos tecidos infectados e sadios, as quais foram desinfestadas superficialmente com álcool 70\% (1 minuto) e hipoclorito de sódio 1\% (1 minuto) e lavadas em água destilada por duas vezes; em seguida, transferidas para placa de Petri contendo meio de cultura MEA (extrato de malte-ágar) $2 \%$, e incubadas por 7 dias em câmara de crescimento à temperatura de $25 \pm 2^{\circ} \mathrm{C}$ e fotoperíodo de 12 horas. Após a constatação de crescimento fúngico foram retirados fragmentos de meio contendo micélio e levados ao microscópio de luz para a identificação do patógeno (Sutton, 1980).

Foram obtidos dois isolados das plantas sintomáticas, sendo, um isolado da haste (IH) e outro isolado da folha (IF), identificados como pertencentes ao grupo do $C$. gloeosporioides. De ramos de cafeeiros assintomáticos foi obtido C. dematium (ID). Após fragmentos das colônias foram transferidos para novas placas contendo MEA $2 \%$, para purificação dos isolados e, após sete dias de crescimento nas mesmas condições descritas anteriormente, foi confirmada a identificação pelos mesmos critérios.

Neste estudo também foi utilizado um isolado de fruto de mangueira com sintomas de antracnose (IM) que passou pelos mesmos critérios de isolamento e identificação descritos para os isolados de cafeeiro e foi identificado como 
um fungo do grupo do C. gloeosporioides. O objetivo de se utilizar este isolado foi verificar como se comportava um isolado de C. gloeosporioides de outra espécie de planta quando inoculado em cafeeiro.

\section{Inoculação}

Em placas de Petri, contendo duas folhas de papel de filtro, previamente esterilizadas foram colocados dois suportes de plástico, desinfestados em hipoclorito e álcool $70 \%$. Em um dos suportes colocou-se o hipocótilo (três centímetros) e no outro, folhas de plântulas, cultivar Rubi, obtidas conforme descrito anteriormente. Com agulha entomológica, feriu-se o hipocótilo e as folhas e, em seguida, depositou-se $10 \mu \mathrm{L}$ de cada suspensão de conídios, ajustada a $10^{6}$ conídios $\mathrm{mL}^{-1}$ com uma micropipeta automática. As testemunhas foram inoculadas com água autoclavada. Para cada isolado, foram preparadas onze placas, sendo uma para cada tempo amostrado. O papel de filtro foi molhado com água destilada esterilizada para promover câmara úmida. As placas de Petri foram incubadas em câmara de crescimento à temperatura de $25 \pm 2{ }^{\circ} \mathrm{C}$ e fotoperíodo de 12 horas.

\section{Coleta de amostras}

Amostras foram coletadas em intervalos de tempo pré-determinados $(2,3,5,12,16,24,48,72,96,114$ e 144 horas), e transferidas para microtubos de $1,5 \mathrm{~mL}$ contendo fixador Karnovsky modificado (glutaraldeido 2,5\%, paraformaldeido $2,0 \%$, tampão cacodilato $0,05 \mathrm{M}, \mathrm{pH} 7,2$ ), por um período mínimo de 24 horas, para serem preparadas e analisadas ao microscópio eletrônico de varredura.

\section{Preparo das folhas para análise em MEV}

As amostras de folhas inoculadas, duas folhas para cada isolado em cada tempo, foram retiradas do fixador Karnovsky modificado e transferidas para microtubos de $1,5 \mathrm{~mL}$ contendo tampão cacodilato de sódio $0,05 \mathrm{M}$, onde permaneceram por dez minutos. O tampão foi trocado três vezes. Após esta etapa as amostras foram imersas em solução de tetróxido de ósmio $1 \%$ em água destilada, por duas horas à temperatura ambiente. Subseqüentemente as amostras foram lavadas com água destilada por três vezes e desidratadas em série crescente de concentração de acetona $(25 \%, 50 \%, 75 \%, 90 \%$ - 10 minutos cada e $100 \%$ por três vezes de 10 minutos). Após esta etapa, as amostras foram levadas ao aparelho de ponto crítico (Balzers CPD 030) para completar a secagem pelo método do ponto crítico do $\mathrm{CO}_{2}$. Após completa a desidratação as amostras foram cuidadosamente montadas em "stubs" (cilindros de alumínio com $12 \mathrm{~mm}$ de diâmetro) cobertos com fita de carbono dupla face para aderência das amostras e cobertas com 20nm de ouro, em aparelho Balzers SCD 050. A observação e documentação foram realizadas em MEV Evo 40XVP, utilizando $20 \mathrm{KeV}$ de voltagem de aceleração e $9 \mathrm{~mm}$ de distância de trabalho. As imagens geradas depois de gravadas foram visualizadas e trabalhadas no software photopaint do pacote Corel Draw 12.

\section{Preparo dos hipocótilos para análise em MEV}

Amostras de hipocótilos foram retiradas do fixador e transferidas para glicerol $30 \%$ por 30 minutos; em seguida, imersas em nitrogênio líquido e fragmentadas com bisturi sobre placa de metal, mantida a temperatura do nitrogênio líquido. Após seccionados transversalmente, 15 fragmentos de hipocótilos foram colocados em tubos de $1,5 \mathrm{~mL}$ contendo água destilada e preparados para MEV, seguindo a metodologia descrita acima.

\section{RESULTADOS E DISCUSSÃO}

\section{Aderência e germinação de conídios}

A aderência dos conídios de todos os isolados foi maior nas regiões onde havia maiores depressões, ou seja, nas regiões sobrejacentes às paredes anticlinais do hipocótilo (Figura 1A) e nas junções das células da epiderme das folhas e ou dos estômatos (Figura 1B). Esta adesão não só assegura que o patógeno permaneça em contato com o hospedeiro pelo tempo necessário para a penetração, mas também favorece a infecção da hifa no local da penetração. A adesão do esporo à superfície do hospedeiro influencia no desenvolvimento da doença, pois, uma rápida adesão dos conídios é relevante para o sucesso do estabelecimento do patógeno (Mercure et al., 1994).

Foi observada uma protuberância sugestiva de septo nos conídios, duas horas após a inoculação no isolado IH (Figura 1C) e três horas para os demais isolados. Como observado em conídios de C. graminicola (Skoropad, 1967) e C. truncatum (Staples et al., 1976), o início da germinação também é precedido da formação de um septo.

A emissão do tubo germinativo foi observada a partir de cinco horas para isolados de C. gloeosporioides e 12 horas após para $C$. dematium. A germinação de conídios dentro do gênero Colletotrichum é bastante variável, iniciando-se entre 3 e 48 horas (Bailey et al., 1992; Kumar et al., 2001; Pereira et al., 2005) dependendo, ainda, de fatores externos como temperatura (Orozco, 2003), presenças de compostos químicos (Liu \& Kolattukudy, 1998) e presença de materiais exógenos (Bailey \& Jeger, 1992; Skipp et al., 1995). Pereira e colaboradores (2005) verificaram que a germinação de C. gloeosporioides em hipocótilos de cafeeiro, ocorreu 6 horas após a inoculação; este tempo também foi necessário para germinação de conídios de $C$. acutatum em Pinus radiata (Nair \& Corbin, 1981).

Os tubos germinativos foram formados, tanto nas extremidades quanto lateralmente. C. gloeosporioides emitiu apenas um tubo (Figura 1F) enquanto que $C$. dematium emitiu um, dois, e até três tubos germinativos (Figura 1E). Estes resultados são reforçados por outros autores que verificaram eventos semelhantes, mostrando que a emissão múltipla de tubo germinativo é comumente relatada para este gênero (Nair \& Corbin, 1981; Roberts \& Snow, 1984; Manandhar et al., 1985; Pereira et al. 2005). 

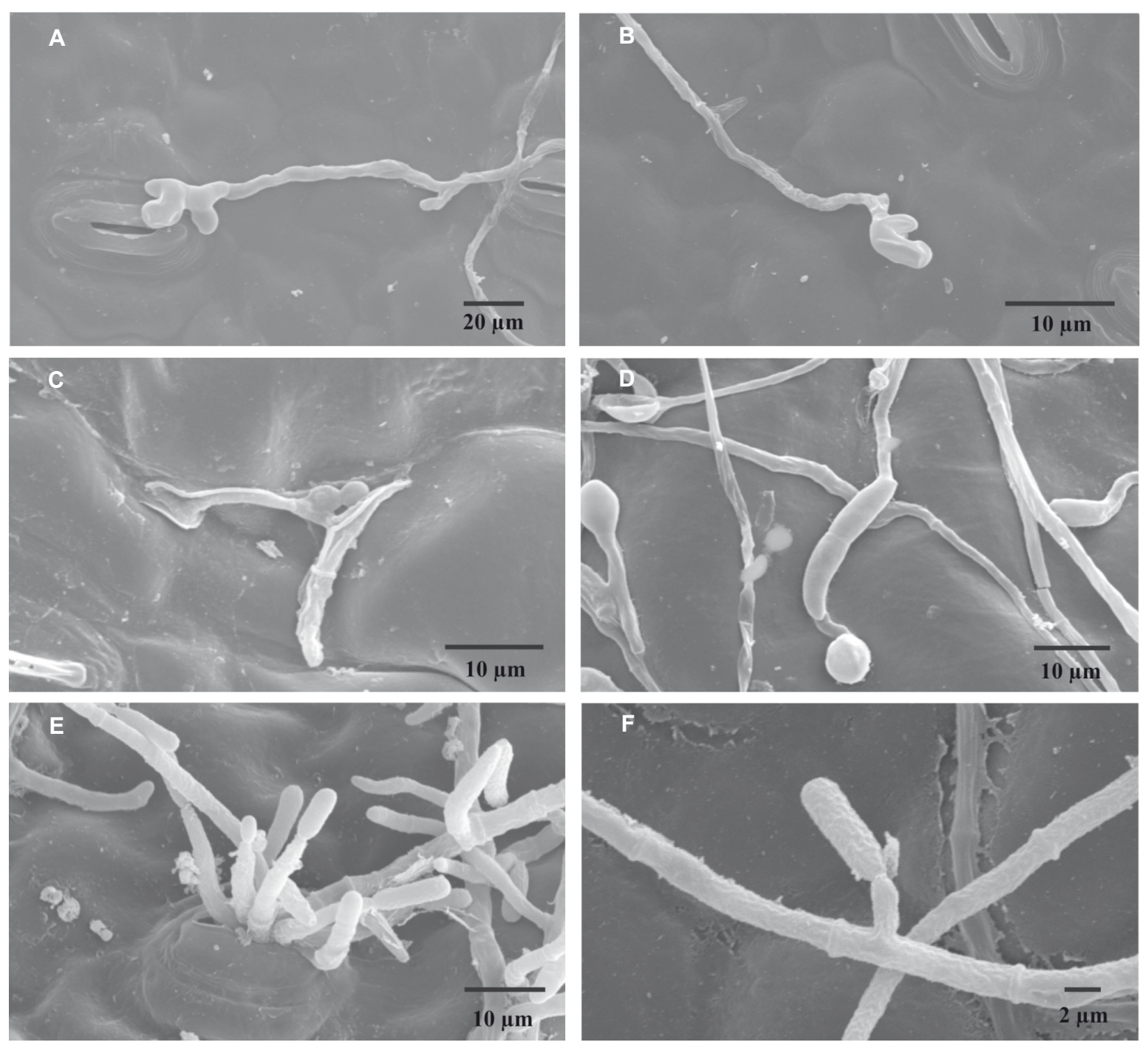

FIG. 1 - Eletromicrografia de varredura mostrando eventos de pré-penetração de Colletotrichum ssp. A. aderência de conídios de C. gloeosporioides em regiões anteclinais do hipocótilo; B. em depressão de células subsidiarias do aparelho estomático; C. septação de conídios (seta) de C. gloeosporioides IH duas horas após a inoculação; D. formação de apressório em $C$. dematium a partir de um tubo germinativo curto, doze horas após a inoculação (setas); E. emissão de múltiplos tubos germinativos (setas) em C. dematium; F. apressório (seta) formado na extremidade do tubo germinativo de C. gloeosporioides, 24 horas após a inoculação.

\section{Formação de apressório.}

Foram observados apressórios apenas para o isolado de $C$. dematium (12 HAI) e para o isolado de folha de C. gloeosporioides (IF) (24 HAI). Garcia (1999) observou a formação de apressório em tempos semelhantes, penetração direta dos tecidos 19 horas após inoculação. O crescimento do tubo germinativo foi variável antes da emissão do apressório, sendo verificado tubos germinativos curtos e longos (Figuras 1D e F, repectivamente). Após o alongamento do tubo germinativo C. gloeosporioides (IF) formou apressório globoso a subgloboso, de contorno regular, delimitado por um septo (Figura 1F). De acordo com Chen et al. (2004), a penetração da hifa de apressórios de C. kahawae está relacionada com a pressão de turgor do apressório e que esta pressão pode ser influenciada por vários fatores como melanização do apressório e cutinase presente nos conídios. A importância do apressório para a penetração não foi avaliada em nosso estudo.

Em C. dematium (ID) observou-se diferentes tipos de apressórios: Trilobados, em forma de vírgula, em forma de pé e globosos no final de tubos germinativos curtos a 96 horas após a inoculação (Figura 2). Esta variação de formas de apressórios foi verificada também para C. gloeosporioides em cafeeiro por Pereira et al. (2005). 

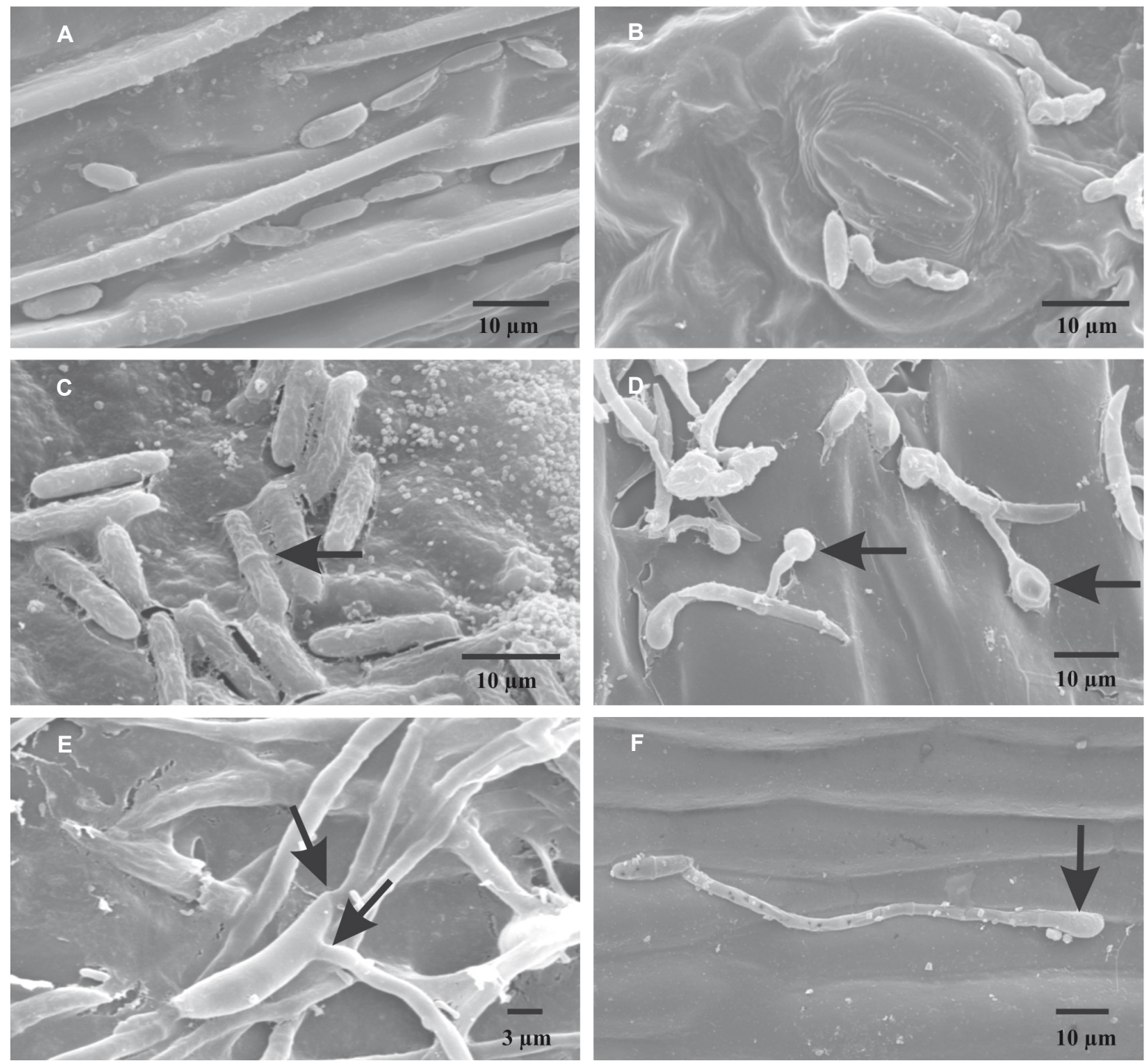

FIG. 2 - Eletromicrografia de varredura mostrando diferentes tipos de apressórios produzidos por C. dematium e formação de conidióforos por C. gloeosporioides. A. Apressório trilobado de C. dematium; B. apressório de C. dematium em forma de vírgula; C. apressório de $C$. dematium em forma de pé; D. apressório globoso de contorno regular em C. dematium; E. conidióforo de C. gloeosporioides saindo de estômato com células conidiogênicas e conídios enteroblásticos fialídicos; $\mathbf{F}$. célula conidiogênica formada lateralmente em hifa.

\section{Conidiogênese e formação de acérvulo}

Acérvulo foi observado no isolado (IH) de $C$. gloeosporioides e no isolado de C. dematium (ID). No entanto, o isolado IF exibiu conidióforo, mostrando uma conidiogênese enteroblástica fialídica típica do gênero Colletotrichum, fenômeno observado em tecido do hipocótilo. O mesmo foi verificado no isolado da haste 24 HAI (Figura 2E) e no isolado de manga 96 horas após a inoculação. Células conidiogênicas foram produzidas lateralmente em hifas (Figura 2F), nos isolados IM e no IH $48 \mathrm{HAI}$

O isolado da haste produziu acérvulo a partir de conidióforos formados sobre uma base estromática subcuticular que rompeu a cutícula 72 HAI. Setas contendo conídios nas extremidades foram observadas até 144 HAI (Figura 3A), quando a produção de acérvulo foi bastante acentuada (Figura 3B). Os acérvulos produzidos por $C$. dematium foram observados em tecidos do hipocótilo a partir de $96 \mathrm{HAI}$, com produção de setas pontiagudas sem produção de conídios nas extremidades (Figura 3C). Até o presente, apenas um autor descreveu a formação de acérvulo em tecidos de cafeeiro inoculados com C. gloeosporioides em microscópio de luz, nove dias após a inoculação (Orozco, 2003). 

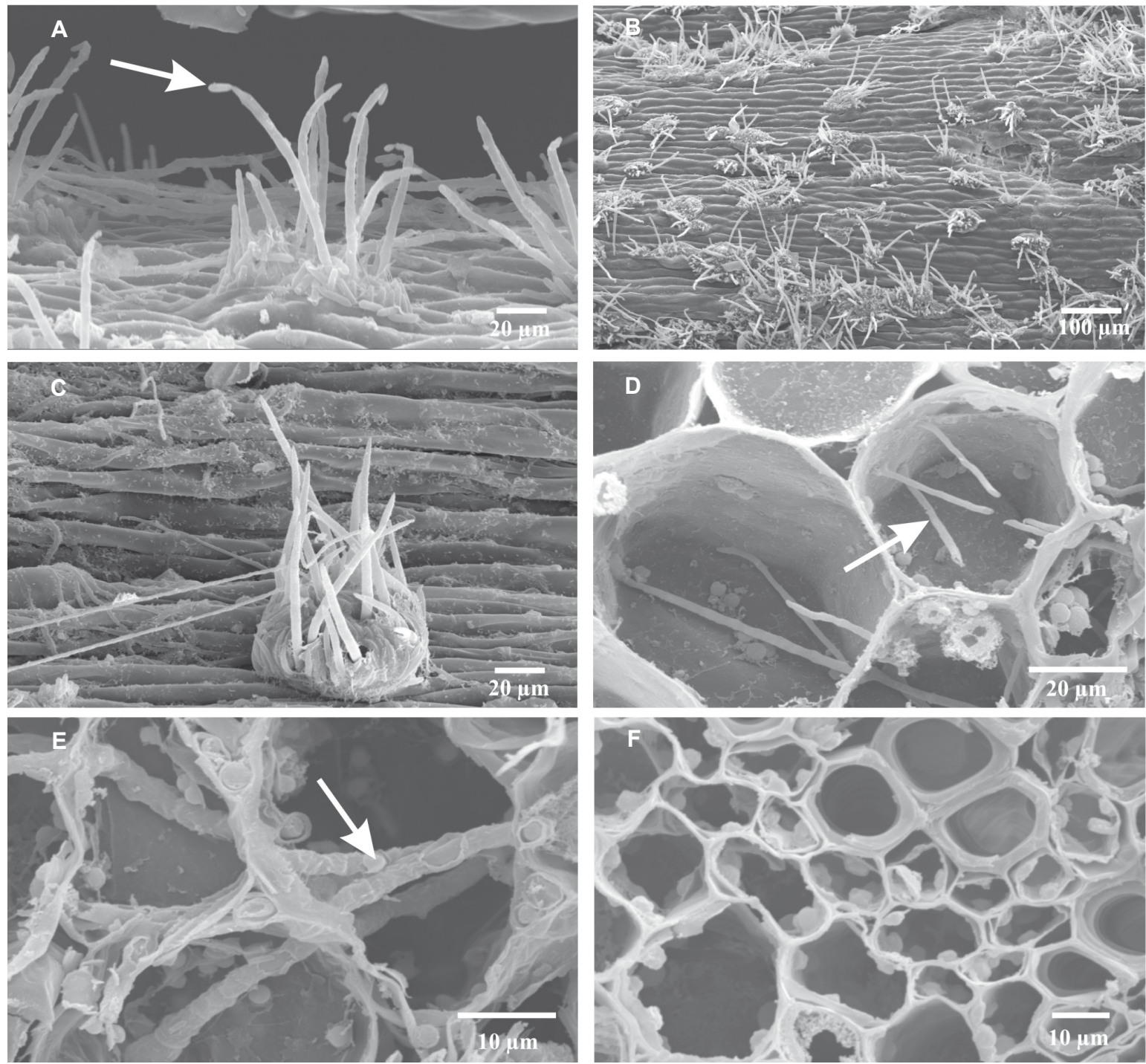

FIG. 3 - Eletromicrografia de varredura mostrando colonização e reprodução de C. gloeosporioides e C. dematium. A. acérvulos formados por C. gloeosporioides $(\mathrm{IH})$ em base estromática com setas pontiagudas produzindo conídios na extremidade; B. grande quantidade de acérvulos formados por C. gloeosporioides (IH) em tecido de hipocótilos 114 horas após a inoculação; C. acérvulo formado por C. dematium em tecido de hipocótilo 72 horas após a inoculação; D. hifas de C. gloeosporioides (IM) penetrando as células do córtex; E. hifas de C. gloeosporioides (IH) destruindo tecidos; F. corte transversal do hipocotilo de plântula testemunha mostrando vasos do xilema e células do córtex sem colonização.

\section{Colonização dos tecidos internos}

Tecidos do córtex, xilema e floema dos hipocótilos e mesófilos de folhas foram invadidos por hifas de todos os isolados a partir de $48 \mathrm{HAI}$ e isso foi evidenciado até 144 HAI. As hifas perfuraram as células e foram colonizando todo o tecido hospedeiro em todas as direções. Uma vez tendo penetrado no mesófilo foliar e ou no córtex de hipocótilos, a hifa aumentou seu diâmetro em duas a três vezes e colonizou os espaços intercelulares causando destruição extensiva dos tecidos (Figura 3E), o que não ocorreu no tecido das plantas testemunhas inoculadas com água autoclavada esterilizada (Figura 3F).
Embora outros trabalhos tenham mostrado eventos de pré e pós-penetração, nenhum tinha documentado ainda estes eventos com isolados de diferentes espécies de Colletotrichum em plantas de cafeeiro (Garcia, 1999; Chen, 2002; Chen et al., 2004). Foi mostrado que os isolados testados neste estudo não apresentam especificidade em relação ao hospedeiro, já que o isolado de manga também colonizou os tecidos de plântulas de cafeeiro.

Na tabela 1 estão apresentada, de forma sumarizada, os eventos formados pelos diferentes isolados. Considerando estes eventos, verificou-se que C. gloeosporioides, isolado de manga, coloniza tecidos de cafeeiro. Entretanto, $C$. 
TABELA 1 - Estruturas formadas pelas espécies de Colletotrichum, inoculados em folhas e hipocótilos de plântulas de café, considerando a evolução no tempo para os diferentes eventos da penetração, colonização e conidiogênese

\begin{tabular}{lllllll}
\hline \hline \multirow{2}{*}{ Isolados $^{1}$} & \multicolumn{5}{l}{ Estruturas formadas (tempo após inoculação) } \\
\cline { 2 - 6 } & FSAG & GCFTG & FA & PC & PA & MP \\
\hline C. gloeosporioides (IH) & 2 horas & 5 horas & $\mathrm{NO}^{3}$ & 24 horas & 72 horas & $\mathrm{F}^{4}$ \\
C. gloeosporioides (IF) & 3 horas & 5 horas & 24 horas & 48 horas & $\mathrm{NO}^{3}$ & $\mathrm{~F}^{4}$ \\
C. gloeosporioides (IM) & 3 horas & 5 horas & $\mathrm{NO}^{3}$ & 96 horas & $\mathrm{NO}^{3}$ & $\mathrm{~F}^{4}$ \\
C. dematium (ID) & 3 horas & 12 horas & 12 horas & $\mathrm{NO}$ & 96 horas & $\mathrm{F}^{5} \mathrm{E}^{5}$ \\
\hline
\end{tabular}

(FSAG) ${ }^{2}$ Formação de septo antes da germinação; (GCFTG) ${ }^{2}$ Germinação do conídio e formação do tubo germinativo; $(\text { FA })^{2}$ Formação de apressório; (PC $)^{2}$ Produção de conidióforo; $(\text { PA })^{2}$ Produção de acérvulo; $(\mathbf{M P})^{2}$ Modo de penetração; $(\mathbf{N O})^{3}$ Não observado até $114 \mathrm{~h}$ após inoculação; $(\mathbf{F})^{4}$ penetração por ferimento; $(\mathbf{F} / \mathbf{E})^{4}$ penetração por ferimento e estômato; (IH $)^{1}$ Isolado da haste de cafeeiro; (IF $)^{1}$ Isolado de folha cafeeiro; $\left(\right.$ IM) ${ }^{1}$ Isolado de manga $(\mathbf{C M L} 461)^{1}$ da Coleção Micológica de Lavras; (ID) ${ }^{1}$ Isolado de cafeeiro sadio.

gloeosporioides $(\mathrm{IH})$ mostrou-se mais infectivo durante o processo de colonização e formação de estruturas reprodutivas. Neste sentido, este estudo é pioneiro na demonstração desses processos em plantas de cafeeiro com diferentes isolados. Outros estudos devem ser desenvolvidos, porque há evidências que existam ainda outras espécies de Colletotrichum em cafeeiro, ainda não estudadas, e também outras estratégias de infecção.

\section{AGRADECIMENTOS}

A primeira autora agradece à Coordenação de Aperfeiçoamento de Pessoal de Nível Superior - CAPES pela concessão de bolsa de estudos.

\section{REFERÊNCIAS BIBLIOGÁFICAS}

BAILEY, J.A \& JEGER, M.J. Colletotrichum: biology, pathology and control. Kew. CAB International. 1992.

GARCIA, I. Histologia e ultra-estrutura do processo de infecção de Colletotrichum kahawae e C. gloeosporioides em Coffea arábica. Dissertação de Mestrado. Universidade Técnica de Lisboa. Lisboa. 1999.

CHEN Z. Morphocultural and pathogenic comparisons between Colletotrichum kahawae and C. gloeosporioides isolated from coffee berries. PhD Thesis. Universidade Técnica de Lisboa. Lisboa. 2002.

CHEN, Z., NUNES, M.A. \& SILVA, M.C. Appressorium turgor pressure of Colletotrichum kahawae might have a role in coffee cuticle penetration. Mycologia 96:1199-1208. 2004.

DIAS, M.D., POZZA, E.A., ABREU, M.S. \& OROZCO MIRANDA, E.F. Efeito da temperatura no crescimento micelial, produção e germinação de conídios de Colletotrichum spp. isolados de Coffea arabica L. Ciência e Agrotecnologia 29:545552. 2005.

DILLARD, H.R. Effect of temperature, wetness duration, and inoculation density on infection and lesion development of Colletotrichum coccodes on tomato fruit. Phytopathology 79:1063- 1066. 1989.

ESTRADA, A.B., DODD. J.C. \& JEFFRIES, P. Effect of humidity and temperature on conidial germination and appressorium development of two Philippine isolates ofthe mango anthracnose pathogen Colletotrichum gloeosporioides. Plant Pathology 49: 608-618.2000

GOLDEN ROBERTS, R. \& SNOW, J.P. Histopathology of cotton rot caused by Colletotrichum capsici. Phytopathology 74:390-397. 1984.

KUMAR, V., GUPTA, V.P., BABU, A.M., MISHRA, R.K., THIAGARAJAN, V. \& DATTA, R.K. Surface ultra-structural studies on penetration and infection process of Colletotrichum gloeosporioides on Mulberry Leaf Causing Black Spot Disease. Phytopathology 149:629-633. 2001.

LIU, Z. M. \& KOLATTUKUDY, P.E. Identification of a gene product induced by hard-surface contact of Colletotrichum gloeosporioides conidia as an ubiquitin-conjugating enzyme by yeast complementation. Journal Bacteriology 180:3592-3597. 1998.

MANANDHAR, L.B., KUWAR, I.K., TRIBHUWAN, S.G., HARTMAN, L. \& SINCLAIR, B. Penetration and infection of soybean leaf tissues by Colletotrichum truncatum and Glomerella glycines. Phytopathology 75:705-709. 1985.

MENEZES, M. \& SILVA-HANLIN, D.M.W. Guia prático para fungos fitopatogênicos. Imprensa Universitária, UFRPE, 1997.

MERCURE, E.W., KUNOH, H. \& NICHOLSON, R.L. Adhesion of Colletotrichum graminicola conidia to corn leaves: a requirement for disease development. Physiological and Molecular Plant Pathology 45:407-720. 1994.

NAIR, J. \& CORBIN, J.B. Histopathology of Pinus radiata seedlings infected by Colletotrichum acutatum f. sp. pinea. Phytopathology 71:777-783. 1981.

OROZCO, M.E.F. Caracterização morfológica, molecular, bioquímica e patogênica de isolados de Colletotrichum spp. associados ao cafeeiro em Minas Gerais e comparação com Colletotrichum kahawae. Tese de Doutorado. Universidade Federal de Lavras. Lavras MG. 2003.

PEREIRA, I.S., ABREU, M.S., FERREIRA, J.B. \& ALVES, E. 
Pré-infecção de Colletotrichum gloeosporioides em hipocótilos de cafeeiros inoculados artificialmente. Anais, 4 Simpósio de Pesquisa dos Cafés do Brasil. CD. Londrina, 2005.

PERFECT, S.E., HUGHES, H. B., O'CONNELL, R.J. \& GREEN, J.R. Colletotrichum: a model genus for studies on pathology and fungal-plant interactions. Fungal Genetics and Biology 27:186198. 1999.

ROBERTS, R.G \& SNOW, J.P. Histopathology of cotton ball rot caused by Colletotrichum capsici. Phytopathology 74:390-397. 1984.

SKIPP, R.A., BEEVER, R.E., SHARROCK, K.R., RIKKERINK, E.H.A. \& TEMPLETON, M.D. Colletotrichum. In: Kohmoto, K., Singh, U.S. \& Singh, R.P. (Eds.) Pathogenesis and host specificity in plant diseases. Oxford. Oxford Pergamon - Elsevier
Science. 1995. pp. 119-142.

SKOROPAD, W.P. Effect of temperature on the ability of Colletotrichum graminicola to form appresoria and penetrate barley leaves. Canadian Journal of Plant Science 47:431-434. 1967.

STAPLES, R.C., LACCETTI, L. \& YANIV, Z. Appresorium formation and nuclear division in Colletotrichum truncatum. Archives of Microbiology 109:75-84. 1976.

SUTTON, B.C. The Coelomycetes. Surrey. CMI Kew. 1980.

SUZUKI, K., FURUSAWA, I., ISHIDA, N. \& YAMAMOTO, M. Protein synthesis during germination and appressorium formation of Colletotrichum lagenarium spores. Journal of General Microbiology 124:61-69. 1981.

Recebido 27 Março 2006 - Aceito 20 Dezembro 2007 - FB 6038 